\title{
EDUCAÇÃO FÍSICA ESCOLAR E INCLUSÃO: ALGUNS \\ DESENCONTROS
}

DOI 105902/0102830812517

Data de submissão: 08/01/2014 Data de aceite: 04/11/2014

Flávia Martinelli Ferreira

Faculdade de Educação Física da

Universidade Estadual de Campinas

flaviamartinelli@uol.com.br

Jocimar Daolio

Faculdade de Educação Física da

Universidade Estadual de Campinas

jocimar@fef.unicamp.br

RESUMO: O artigo é composto de uma revisão bibliográfica sobre a produção teórica envolvendo o tema da Inclusão e a educação física escolar. Questões sobre a produção deste conhecimento e os significados sobre estar incluído nortearam o debate que realizado confrontando diferentes referenciais teóricos. A discussão é apresentada com autores que conceituam a Inclusão, abordando à Educação Física escolar e seu encontro com este conceito. Inspirados por essa diversidade teórica, são elaboradas reflexões a partir de descompassos destes pensamentos, a fim de contribuir para a reflexão do tema estudado. Diante do fracasso frente à diversidade devemos repensar o conceito de Inclusão.

Palavras-chave: Educação física. Pessoas com Deficiências. Diversidade cultural 


\section{Introdução}

Este artigo é composto de uma revisão bibliográfica sobre as produções teóricas que envolvem o tema da Inclusão e seu encontro com as aulas de educação física escolar. Os autores que serão destacados foram selecionados para apontar como este conhecimento tem sido produzido em nossa área, estabelecendo um diálogo entre estes diferentes referenciais teóricos sobre inclusão e educação física escolar. O levantamento sobre a literatura que tematiza a Inclusão nos permitiu compreender como o conceito foi estabelecido e incorporado na educação física escolar. Buscamos, em outro sentido, refletir as questões que têm distanciado estas produções teóricas das práticas educativas encontradas nas escolas.

O debate será iniciado em um primeiro momento com as definições sobre o que consideramos ser papel da educação física escolar, seus conhecimentos e especificidades. Esta especificidade das aulas de educação física e de seus conhecimentos que são construídos com o corpo é exposta inicialmente para que seja possível demonstrar o desencontro entre o que tomamos como objeto de ensino e o conceito de Inclusão inserido neste contexto.

Em seguida relataremos os percursos do conceito de Inclusão para elucidar como esta temática emergiu e penetrou nosso campo teórico, produzindo diferentes conhecimentos sobre o tema. Com isso, será possível apontar alguns desencontros sobre o referencial teórico estudado e as práticas inclusivas. Inspirados por essa diversidade teórica, finalizaremos com a elaboração de algumas considerações sobre o confronto destes pensamentos.

Consideramos que a educação física escolar como componente curricular da educação básica deve introduzir o aluno na cultura corporal de movimento. Com isso, permite ao aluno fazer análises críticas sobre conhecimentos referentes à cultura corporal de movimento bem como conhecer, compreender e reconstruir esta cultura (BETTI; ZULIANI 2002). A partir destas reflexões entendemos como o autor que o conhecimento específico da educação física não pode ser dissociado de uma vivência concreta da cultura corporal de movimento.

Ao destacar a especificidade da educação física como componente curricular, Daolio (2007) argumenta que: 
O profissional de educação física não atua sobre o corpo ou com o movimento em si, não trabalha com o esporte em si, não lida com a ginástica em si. Ele trata do ser humano nas suas manifestações culturais relacionadas ao corpo e ao movimento humanos, historicamente definidas como jogo, esporte, dança, luta e ginástica. O que irá definir se uma ação corporal é digna de trato pedagógico pela educação física é a própria consideração e análise desta expressão na dinâmica cultural específica do contexto onde se realiza (DAOLIO, 2007, p.2-3)

As propostas educativas homogêneas e estratégias excludentes não têm se mostrado suficientes para dar conta da diversidade que encontramos nos ambientes escolares e, do mesmo modo, nas aulas de educação física. Isto porque os conhecimentos que devem ser construídos durante as aulas devem passar pelo corpo dos alunos, sendo aprendidos ou, dito de outra forma, incorporados.

No entanto, não é raro observamos alunos que atravessam o sistema educacional sem incorporar conhecimentos nas aulas de educação física e, ainda que tenham a possibilidade de construir conhecimentos com o corpo fora das aulas, este conhecimento não passa pelo trato pedagógico caro à educação física escolar. Considerando este panorama, temos como objetivo versar sobre o conceito de Inclusão atrelado as aulas de educação física e suas especificidades, destacando os desdobramentos e desencontros produzidos deste encontro.

\section{A Educação Física Escolar}

Quando chegam à escola, grande parte das crianças consegue andar, correr e saltar. Segundo Soares (1996), os atos de andar, correr e saltar são cotidianos, partes da vida em sociedade, são traços culturais destas ações já inscritos de diferentes formas nos corpos dos alunos. Estes atos da vida diária foram transformados em códigos ao longo da história e esta "codificação" (SOARES, 1996) é o objeto de ensino da educação física na escola.

Atualmente, chegam à escola algumas crianças não conseguem andar, correr, saltar, ouvir ou falar. Este não-fazer, que também faz parte da vida em sociedade, são alguns dos traços culturais que acentuam nossas diferenças e já estão inscritos nos corpos dos alunos, sendo dignos também do trato pedagógico dado pelas aulas de educação física.

Consideramos que o conceito de Inclusão deve ser definido, nas aulas de educação física, diferentemente do que tem sido discutido, como a apreensão desta "codificação" e como o acesso ao conhecimento específico das aulas de educação física, sendo excluídos 
os alunos aos quais não oportunizamos o acesso a estes códigos e aos conhecimentos específicos. Estar incluído nas aulas de educação física implica ter acesso ao conhecimento específico da área e oportunidade de construir questões mais elaboradas relacionadas ao corpo e ao movimento.

A Inclusão defendida neste artigo se distancia portanto de outros autores como Pedrinelli (1994) e Seabra Junior (2006) que definem a Inclusão nas aulas de educação física como a participação de todos com respeito às suas limitações, sendo o professor capaz de promover autonomia e ênfase no potencial de cada um em seu domínio motor.

Segundo Seabra Junior (2006), os alunos excluídos das aulas, principalmente nas séries iniciais, provavelmente apresentarão restrição de movimentos futuramente, que resultarão em defasagens de aprendizagem. O autor considera que estas defasagens estão expressas no rendimento escolar do aluno que pode apresentar dificuldade em fixar atenção, organizar o espaço, ler, escrever, desenhar números e outras dificuldades de ordem afetiva e social.

Reiteramos a definição anterior na qual asseguramos que um aluno incluído tem o acesso ao conhecimento específico da educação física, seus códigos e linguagens estabelecidos historicamente, antes de dar continuidade ao debate sobre a Inclusão nas aulas de educação física escolar. Neste sentido, acreditamos ser a educação física responsável pela admissão do aluno na cultura corporal de movimento sendo considerado como rendimento escolar em nossas aulas a apropriação deste conhecimento específico.

O Decreto n. 21.241 criado em 1932 consolidou as disposições sobre a organização do ensino secundário e das universidades brasileiras. Se a este decreto foram adicionadas, seis anos depois, normas que proibiam alunos cujo estado patológico os impedia de frequentar as aulas de educação física de se matricularem em estabelecimentos de ensino secundário (SOLER, 2005, p.65), podemos considerar que durante um longo período as aulas de educação física e a escola tinham um público que se pretendia homogêneo.

A escola, instituição onde sujeitos são formados como seres uniformes, ao tentar tornar alunos eficientes e disciplinados, tentou consertá-los (BRACHT; ALMEIDA; GOMES, 2010). Segundo os autores a busca pela ordem e pela uniformidade suscitou a necessidade de excluir aqueles considerados indesejáveis. Estas exclusões, sempre estiveram acompanhadas daqueles que deveriam ser incluídos e são destacadas como o binômio 
exclusão e inclusão pelo autor. Amparados pelos estudos sobre a modernidade feitos pelo sociólogo Bauman, afirmam que a questão da normalidade é essencial para que a sociedade busque e mantenha uma ordem social, evitando assim, a desordem. Os autores considera que a exclusão têm sido a forma encontrada pela sociedade mais legítima de afastar estes "anormais".

Segundo os autores "o projeto de escolarização não reservou nenhum lugar às diferenças e às múltiplas formas de vida e tradições locais que estavam lá" (BRACHT; ALMEIDA; GOMES, 2010, p.5), sendo todas as diferenças entre os ditos normais e anormais sempre suprimidas ao invés de exaltadas.

No entanto, o modelo contido atualmente nos Parâmetros Curriculares Nacionais (PCNs) para o ensino fundamental, de quinta a oitava séries (BRASIL, 1998, p.19) tem como princípio básico considerar que estas aulas sejam dirigidas a todos:

A sistematização dos objetivos, conteúdos, processos de ensino e aprendizagem e avaliação têm como meta a Inclusão do aluno na cultura corporal de movimento por meio da participação e reflexão concreta e efetiva. Busca-se rever o quadro histórico de seleção entre indivíduos aptos e inaptos para práticas corporais, resultante da valorização exacerbada do desempenho e da eficiência (BRASIL, 1998, p.19).

As inúmeras diferenças ${ }^{1}$ incluídas e excluídas pela escola agora compõem as aulas de educação física de diferentes maneiras e confirmam a necessidade da aula ser um lugar de aprender coisas, e não o espaço em que alunos que dominam técnicas elementares vão aperfeiçoar o que já sabem, enquanto alunos que não sabem continuam sem a oportunidade de aprender (SOARES, 1996).

Sendo assim, chegam à escola atualmente todos os alunos diferentes - que foram historicamente negligenciados pela educação e pela sociedade. As aulas de educação física são então compostas, cada vez mais, por alunos que possuem diferenças inscritas em seus corpos e suas diferentes culturas. Entretanto ainda que componham as aulas de educação física, destacamos um descompasso entre estas aulas e a inclusão destes alunos

Embora asseguradas por Lei como mencionado anteriormente, as inclusões e exclusões são legitimadas por um discurso de normalidade e pela implementação de um modelo

\footnotetext{
${ }^{1}$ Entendemos como Gusmão (2003) que igualdade e diferença não revelam-se como categorias absolutas mas dependem das relações sociais envolvidas e de exercícios de poder e de dominação. Neste sentido, uso do conceito de diferença proveniente dos estudos da Antropologia é pertinente para ampliar as discussões sobre Inclusão presentes neste trabalho.
} 
educacional que sustenta práticas segregacionárias e que costuma limpar e extinguir imprecisões e ambivalências presentes em nossa sociedade e, portanto, na escola. Avançaremos com apontamentos bibliográficos capazes de delinear o conhecimento produzido tanto no campo teórico da educação quanto na área da educação física escolar sobre a temática da Inclusão, destacando o descompasso entre estas produções teóricas.

\section{O Caso Da Inclusão No Brasil}

O princípio básico atribuído à Inclusão surge na década de 1950 com o nome de princípio da normalização. Este princípio opõe-se às alternativas criadas com atendimentos segregacionistas ao qual estavam sujeitas as organizações e metodologias de ensino da educação. Este princípio tem o objetivo de propiciar aos deficientes um modelo de vida que se aproximasse de padrões e condições tidas como normais em nossa sociedade (SASSAKI, 1997).

$\mathrm{Na}$ educação, o conceito de Inclusão, como conhecido atualmente, atravessou diferentes fases e surgiu principalmente para combater o que há muito tem ocorrido em nossa sociedade: a exclusão de deficientes. Este conceito tem sido constantemente repensado, para que a Inclusão de tantos diferentes seja almejada através de um esforço duplo, transformando, simultaneamente, escola e aluno (SASSAKI, 1997).

Embora um consenso sobre o conceito de Inclusão ainda não tenha sido alcançado, segundo Peter Mittler (2003) existem alguns pontos que podem nortear sua compreensão, apesar das dificuldades de restringir o termo ou caracterizá-lo. O autor aponta as mudanças educacionais e a necessidade de garantir o acesso à educação para todos os alunos como importantes em sua elaboração. Isto porque o conceito como conhecemos atualmente atravessou um processo de transformação, sendo antes nomeado de integração ou mainstreaming, segundo Sassaki (1997).

A integração segundo o autor pode ser caracterizada como o momento em que a escola aceitava apenas as deficiências mais adaptáveis, sem elaborar reestruturações ou sofrer grandes alterações. Seguindo os moldes impostos pela integração, os alunos classificados como deficientes buscavam na sociedade um caminho próprio para se desenvolver no âmbito educacional e também no mercado de trabalho (SASSAKI, 1997). 
O conceito de Inclusão discutido no Brasil principalmente a partir da década de 1990, no entanto, propõe tanto um esforço dos próprios alunos quanto da escola para incluir um número maior de alunos no processo educacional, sendo este um de seus diferenciais em relação a outros conceitos como a integração ou o mainstreaming (MITTLER, 2003).

O conceito de mainstreaming surge durante a década de 1980 com o objetivo de levar o maior número possível de alunos deficientes às escolas, ainda sem elaborar modificações na instituição (SASSAKI, 1997). Segundo Mittler (2003), a Inclusão se distingue dos conceitos que a antecedem por sugerir uma reestruturação na escola, que seja capaz de impedir o isolamento de alunos e outras exclusões.

As políticas de inclusão² que discutimos atualmente surgiram inicialmente nos Estados Unidos em meados da década de setenta. Desde então, os princípios norteadores destas políticas como a universalização da igualdade, embora busquem a igualdade de direitos são sustentados na diferença (SILVA, R; SOUSA, S; VIDAL, M, 2008).

Ao analisar a história traçada pela Inclusão no Brasil, mencionada anteriormente, autores apontam três pensamentos distintos que surgiram ao longo da década de 1990: (1) os legalistas, (2) os adaptadores e (3) aqueles que defendem uma nova organização escolar (SILVA, R; SOUSA, S; VIDAL, M, 2008).

A primeira corrente de legalistas, ampara seu discurso de garantia de igualdade de direitos e oportunidades com o respaldo de Leis vigentes em todo território nacional. Por conta das Leis nacionais caracterizadas como indicativas e não prescritivas, esta corrente é criticada por atender ao mesmo tempo interesses neoliberais e de grupos sociais minoritários.

Em segundo lugar surge a corrente nomeada de adaptadores, que propõe a restauração das escolas para que estas sejam capazes de se adaptar às necessidades de grupos outrora excluídos, com a manutenção dos modelos tradicionais de organização escolar.

A terceira corrente indica, no entanto, uma nova forma de organização das escolas e explica que a Inclusão é um caminho que não pode ser alcançado nos modelos que até então têm sido tradicionais na esfera educacional. O argumento construído pela

\footnotetext{
${ }^{2}$ Os exemplos de políticas de inclusão das quais nos referimos podem ser encontrados em: BRASIL, Ministério da Educação e Cultura. Política de Educação Especial na Perspectiva da Educação Inclusiva. Secretaria de Educação Especial. MEC/SEESP, 2007; BRASIL, Ministério da Educação e Cultura. Diretrizes Nacionais para a Educação Especial na Educação Básica. Secretaria de Educação Especial. MEC/SEESP, 2001; Declaração de Salamanca e linha de ação sobre necessidades educativas especiais. Brasília: Corde, 1994; UNESCO. Declaração Mundial de Educação para Todos: Plano de Ação para satisfazer as necessidades básicas do aprendiz. Tailândia, 1990.
} 
terceira corrente indica que as adaptações propostas não são suficientes para dar conta das inclusões almejadas pela educação e o modelo legislativo brasileiro permite que a situação se mantenha quase inalterada, através de leis indicativas que compactuam com a manutenção da exclusão de diferentes alunos por parte das escolas (SILVA, R; SOUSA, S; VIDAL, M, 2008).

Segundo Mittler (2003), para que a Inclusão seja possível são necessárias políticas nacionais, já que a escola, em termos locais, possui limites para efetivar a presença e a participação de todos os alunos. Sendo assim, o autor, que se aproxima de discussões legalistas sobre a Inclusão, acredita que mais instrumentos de incentivo criados através de Leis federais ou estaduais sejam os subsídios necessários para a busca pela Inclusão.

A rigor, destacamos que a educação é assegurada a todos desde a proposta que surge com a primeira Constituição do Brasil independente, em 1824, de uma Educação para todos (JANUZZI, 2006). No entanto, segundo a autora, foram abertas classes e instituições especiais separadas da Educação regular aos alunos deficientes porque estes não foram considerados como constituintes deste "todos".

Na década de 1970 foi criado o Centro Nacional de Educação Especial (CENESP), um órgão específico para a educação especial, medida esta, destaca a autora, considerada como uma política de inclusão a curto prazo. O CENESP, segundo Januzzi (2006), foi extinto durante o governo Sarney (1985-1990) e transformado em SESPE - Secretaria de Educação Especial. O governo alegou em um documento, o Informe SESPE, que esta mudança conferia maior mobilidade institucional.

Em 1990, a SESPE também foi extinta e a educação especial foi para a SENEB Secretaria Nacional de Ensino Básico, especialmente no Departamento de Educação Supletiva e Especial (DESE), (JANUZZI, 2006). Em 1992, ainda durante o governo de Fernando Collor, a autora afirma que a nomenclatura anterior foi alterada novamente e a secretaria nacional foi nomeada de Secretaria de Educação Especial.

Apesar de todas as alterações realizadas na terminologia dos órgãos responsáveis pela educação especial no Brasil e das alterações que foram pensadas em leis federais ou estaduais, poucas mudanças em termos práticos foram conquistadas e apontadas pela autora a partir destas modificações. Ao longo deste período, a educação especial foi deslocada 
de um departamento para outro exaustivamente sem que estas terminologias fossem as responsáveis pela inclusão de um maior número de crianças no campo educacional.

Destacamos que ainda há uma grande distinção entre o que se discute e o que a escola tem praticado em relação à Inclusão. Embora teorias e conceitos tenham se renovado e sido constantemente debatidos, a instituição escolar ainda se mantém distante deste discurso. Ou seja, embora o discurso adentre a instituição escolar de forma mais rápida.

Os apontamentos realizados anteriormente dizem respeito em sua maioria à Inclusão de grupos sociais que, ao longo da história, se mantiveram à margem do sistema educacional brasileiro por diferentes ensejos. Estes grupos dos quais destacamos uma insuficiente admissão ao sistema educacional brasileiro, são classificados de modo mais recente como pessoas com deficiência, quer seja esta deficiência física, auditiva, visual ou intelectual (DIEHL, 2006; DONNELLAN, 2007; JANUZZI, 2007; ALMEIDA; FILHO, 2008).

Porém, ainda que estes excluídos fossem acomodados pelo sistema educacional brasileiro, outros tantos já instaurados nas salas e quadras de aula ainda se mantém distantes e marginalizados deste processo educacional. Destacamos neste artigo que muito do que se tem discutido sobre a Inclusão de pessoas com deficiência, ainda que suficiente - e não é - seria uma busca extenuante e, ainda assim, excludente. Isto porque não considera também as oportunidades distintas a que estamos sujeitos, negros, mulheres, pobres, evangélicos, gordos e outros tantos incluídos e excluídos cotidianamente nas instituições escolares e nas aulas de educação física.

Embora seja possível reconhecer inúmeras conquistas no que se refere à regulamentação de políticas nacionais de incentivo à Inclusão como demonstramos, a reflexão constante sobre os princípios básicos da Inclusão ou a presença de alunos antes abandonados pelo sistema educacional, a seguir serão elaboradas reflexões considerando a trajetória destacada e distintos autores que se debruçaram sobre estes estudos, sendo possível esclarecer e refletir sobre alguns desencontros que tem tornado a educação física escolar e a inclusão mais distantes. 


\section{Educação Física Escolar e Inclusão: Alguns Desencontros}

Apesar de constantes renovações, o conceito de Inclusão ainda se refere primordialmente às questões ligadas às várias diferenças que classificamos como deficiências, deixando escapar suavidades cotidianas alojadas nas aulas de educação física, promovendo seu desencontro com alguns grupos sociais. Assim sendo, as diferenças entre os alunos têm se transformado apenas em justificativas para consentir com a falta de apropriação dos alunos sobre o conhecimento abordado, legitimando também sua ausência nas práticas corporais realizadas em aula.

A Inclusão nas aulas de educação física sugere um acesso ao seu conhecimento específico e a oportunidade de refletir sobre questões relacionadas ao corpo e ao movimento de forma mais ordenada. A educação física deve possibilitar ao aluno análises críticas sobre a cultura corporal de movimento bem como distinguir, compreender e renovar esta cultura (BETTI; ZULIANI 2002). Como mencionado no início do artigo, consideramos que os alunos aos quais não são dadas oportunidades regulares de acesso a estes códigos e ao conhecimento específico da área como excluídos deste processo educacional.

Uma das tensões presentes na área é a dificuldade de que as aulas de educação física consigam atingir ao mesmo tempo todos os alunos e cada um deles (DAOLIO, 2005). Segundo o autor, tensões como esta geram novas reflexões e devem ser discutidas e repensadas, para que possam surgir novas idéias permitindo que as aulas possam enfim alcançar cada aluno e ao mesmo tempo todos eles.

Assim sendo, entendemos que o conhecimento específico da educação física não pode ser desconectado de uma vivência corporal da cultura corporal de movimento e, ao considerarmos alunos como incluídos e excluídos destas aulas, não podemos fazê-lo de forma abrupta. De tal modo, a Inclusão em nossas aulas está relacionada a questões relacionadas ao corpo e ao movimento pensadas de forma mais ordenada, sendo impraticável considerar um aluno inserido nas vivências corporais - que não tenha elaborado considerações ao corpo e ao movimento - prontamente incluído nas aulas. Do mesmo modo, estariam os alunos que elaboram reflexões críticas sobre o conhecimento específico da educação física, mas que estão sentados nas arquibancadas, totalmente excluídos das aulas? 
Daolio (2005) explica que ao consideramos todos os seres humanos como diferentes, as aulas de educação física também devem considerar essa diversidade para que todos os alunos possam se apropriar de seu conhecimento. Outro autor, Oliveira (2006), também argumenta que nossas diferenças são representadas pelos alunos durante as aulas sendo esta uma representação dos diferentes significados estabelecidos pelos alunos por meio das diferenças, ou seja, diferentes significados podem ser constituídos com suas participações ou ausências durante as aulas.

O que nos indica uma inclusão ou uma exclusão depende de outras relações para que possamos considerar o "igual e o diferente" (GUSMÃO, 2003, p.91), não sendo igualdade e diferença categorias absolutas, assim como a inclusão e a exclusão não o são. Tornar a educação um processo de ensino-aprendizagem fundamentado na troca de diferentes é um desafio constante, pois: "Ser diferente é ser desigual? E tornar todos iguais, negando suas diferenças, não seria um ato autoritário, negador do outro, e, como tal, um ato de poder?" (GUSMÃO, 2003, p.90).

De acordo com a autora a questão da diversidade e do encontro entre diferentes culturas sempre estiveram presentes na humanidade. No entanto, estas questões têm aparecido de modo mais intenso nas sociedades modernas e aqueles que são considerados menos mulheres, idosos, crianças, negros ou indígenas - passam a desafiar a ordem instituída (GUSMÃO, 2003, p.54). Neste sentido a Inclusão se distancia das aulas de educação física quando desconsidera esta diversidade de culturas e saberes produzidos pelos seres humanos, considerando esta categoria como absoluta.

A busca por uma ordem instituída nas escolas gerou a necessidade de se excluir aqueles considerados indesejáveis. Esta exclusão, no entanto, sempre esteve acompanhada de tudo aquilo que deveria ser incluído. De um lado, aqueles que pertencem ao quadro linguístico criado, representando a beleza do mundo; não muito distante estão aqueles que distorcem este quadro, representando as sujeiras e ambiguidades da sociedade (BRACHT; ALMEIDA; GOMES, p. 2, 2010).

A Inclusão dos deficientes - que distorcem a beleza do mundo - tem como objetivo, segundo Sassaki (1997) proporcionar a estes um modelo de vida que se aproxime de padrões e condições tidas como normais (e, portanto, mais belas) em nossa sociedade. 
Neste sentido, todos os sujeitos aos quais nos referimos neste artigo, se constituem como aqueles que aceitam aquilo que consideramos igual, semelhante e belo, como a nossa própria imagem.

Tal como a categoria deficientes, a categoria empregada para classificar alunos, assim como outras categorias, que colocam todos em um mesmo buraco, é geral e abstrata, permitindo escapar a diversidade a qual pertencem os seres humanos (GUSMÃO, p. 93, 2003). A autora considera que a escola, apesar de seus esforços - citados acima no contorno de políticas nacionais e reestruturações - se defronta com seu maior enigma: o fracasso diante da diversidade (p. 91, 2003).

Ainda que as discussões sobre a Inclusão tenham avançado e alcançado um maior número de alunos, este conceito construído ao longo de décadas possui diversas lacunas e não tem se mostrado suficiente para dar conta das diferenciações produzidas pelos seres humanos e, assim sendo, das inclusões e exclusões que ocorrem ao longo de um processo educacional nas aulas de educação física, "pois novas formas de inclusão podem (...) estar acompanhadas de práticas pedagógicas de exclusão" (BRACHT; ALMEIDA; GOMES, 2010, p.13).

Para além do "louvor da diferença e das práticas inclusivas" (BRACHT; ALMEIDA; GOMES, 2010, p.13) devemos reconhecer a tarefa de mediação pedagógica dos professores de educação física a cada aula. De acordo com o autor, toda tentativa de incluir provoca também novos excluídos e novos diferentes. As aulas de educação física agora compostas por estes diferentes exigem do professor que este seja um entendedor da tradução destas diferenças para então exercer sua função e dar um trato pedagógico à cultura corporal de movimento, dando a estes também a oportunidade de compreender e reconstruir esta cultura.

\section{Considerações Finais Sobre o Tema}

Ao longo deste artigo buscamos a apropriação de referenciais teóricos sobre a Inclusão e sobre a educação física escolar, para construir algumas considerações através das quais não serão possíveis amplas generalizações, mas que serão pensadas a fim de contribuir para a renovação constante do debate sobre a Inclusão. Ao relatarmos algumas características 
da educação física escolar, percebemos que discussão teórica sobre a temática da Inclusão emergiu e penetrou nosso campo teórico recentemente.

Embora a questão da diversidade sempre estivesse presente em nossa sociedade, estas questões têm aparecido de modo mais intenso, sendo capazes de produzir transformações na área da educação física escolar e constantes reflexões, desafiando tudo aquilo que já havia instituído.

O autor Romeu Sassaki (1997) explica que atualmente o conceito de Inclusão discutido indica uma transformação tanto na escola quanto no aluno para que alcancem um maior número de alunos diferentes incluídos no processo educacional. Podemos afirmar que a renovação deste conceito sugere um descompasso com a educação física escolar, porque deveria implicar também em uma diferente concepção de área, considerando que seus conhecimentos específicos sejam construídos e incorporados durante as aulas. Deste modo avaliamos que a Inclusão não deve tratar apenas do acréscimo de diferentes alunos no processo educacional, mas da busca pela apropriação de conhecimentos específicos levando em consideração uma educação física escolar de qualidade.

Fazer com que as diferenças não sejam precursoras de preconceitos e desigualdades é o ponto de partida para que as aulas de educação física escolar possam assegurar "processos democráticos de acesso ao conhecimento dentro das possibilidades de cada um" (OLIVEIRA, 2010, p. 99). É neste sentido que consideramos a Inclusão um esforço a ser empreendido a cada aula, justamente por considerar seus alunos diferentes, mas não desiguais, sendo necessário mais do que reconhecer estas diferenças e buscar uma suposta igualdade entre os alunos.

São questões como estas que identificam a necessidade de uma busca constante para que todos os alunos estejam incluídos, cada qual a sua maneira, nas práticas corporais que compõem as aulas. Este empenho, para além de adicionar alunos nas aulas, deve considerar suas diferenças e usá-las em benefício das construções destes conhecimentos vivenciados através do corpo no decorrer destas aulas.

Ao considerarmos que a escola está diante de um grande problema, o fracasso diante da diversidade, destacamos a urgência de ampliação de pesquisas que sejam capazes de relativizar o conceito e os princípios da Inclusão discutido em áreas da educação e também 
da educação física escolar. Como identificamos, ainda que seja necessário reconhecer que, certas vezes, incluir um grupo de alunos provoca a exclusão de outros, não devemos perder de vista a busca por situações de inclusão que acarretem em uma maior apropriação dos conhecimentos específicos da educação física escolar.

Consideramos que este artigo não tem como finalidade solucionar os motivos que tem distanciado a teoria e a prática que se refere à Inclusão nas aulas de educação física, mas contribuir com reflexões para continuar este debate. Portanto, pretendemos contribuir com os pensamentos descritos ao longo do artigo nos inúmeros debates acerca da Inclusão nas aulas de educação física e pensadas de forma mais ampla na educação. 


\section{Referências}

ALMEIDA, José J. G; FILHO, Ciro W. de O. Avaliação de pessoas com deficiência visual nas aulas de Educação Física. In: Educação física adaptada: o passo a passo da avaliação. GORLA, José I. (Org.). São Paulo: Phorte, 2008.

BETTI, Mauro; ZULIANI, Luiz R. Educação física escolar: uma proposta de diretrizes pedagógicas. REMEFE - Revista Mackenzie de Educação Física e Esporte, v.1, n.1, jandez, São Paulo: Editora Mackenzie, 2002.

BRACHT, Valter; ALMEIDA, Felipe Q.; GOMES, Ivan M. O local da diferença: desafios à educação física escolar. Revista Pensar a Prática, v.13, n.1, UFG: Goiânia, 2010.

BRASIL, Ministério da Educação e do Desporto. Secretaria de Educação Fundamental. Parâmetros curriculares nacionais para o ensino fundamental. $3^{\circ}$ e $4^{\circ}$ ciclo $\left(5^{a}\right.$ á $8^{a}$ série). Brasília: MEC/SEF, 1998.

DAOLIO, Jocimar. A educação física escolar como prática cultural: tensões e riscos. Revista Pensar a Prática, Goiânia, v. 8, n.2, p. 215-226, 2005.

Educação física e o conceito de cultura. $2^{\mathrm{a}}$ ed. Campinas: Autores Associados, 2007.

DIEHL, Rosilene M. Jogando com as diferenças: jogos para crianças e jovens com deficiência. São Paulo: Phorte, 2006.

DONNELLAN, Anne. Diagnóstico e ficção. In: Nos limites da ação - preconceito, inclusão e deficiência. TUNES, Elizabeth; BARTHOLO, Roberto (Orgs.) São Carlos: EdUFSCar, 2007.

GUSMÃO, Neusa M. M. (Org.) Diversidade, cultura e educação: olhares cruzados. São Paulo: Biruta, 2003.

. Os desafios da diversidade na escola. In: GUSMAO, Neusa (org) Diversidade, cultura e educação: olhares cruzados. São Paulo: Biruta, 2003.

MITTLER, Peter. Educação inclusiva: contextos sociais. Porto Alegre: Artmed, 2003.

OLIVEIRA, Rogério C. de Educação física, escola e cultura: o enredo das diferenças. 2006. 101f. Dissertação (Mestrado em Educação Física) - Faculdade de Educação Física. Universidade Estadual de Campinas, Campinas, 2006. 
. "Não levo jeito, professor...". In: Grupo de Estudo e Pesquisa e Educação Física e Cultura. DAOLIO, Jocimar (Org.). Educação Física Escolar: olhares a partir da cultura. Campinas: Autores Associados, 2010.

PEDRINELLI, V. J. Educação Física Adaptada: conceituação e terminologia. In: Educação Física e Desporto para Pessoas Portadoras de Deficiência. Brasília: MECSEDES, SESI-DN, 1994.

SASSAKI, Romeu K. Inclusão: construindo uma sociedade para todos. Rio de Janeiro: WVA, 1997.

SILVA, Régis H. dos R; SOUSA, Sônia B; VIDAL, Maria H. C. Dilemas e perspectivas da educação física diante do paradigma da inclusão. Revista Pensar a Prática, v.11, n.2, UFG: Goiânia, 2008.

SEABRA JUNIOR, Luiz. Inclusão, necessidades especiais e educação física: considerações sobre a ação pedagógica no ambiente escolar. 119f. 2006. Dissertação (Mestrado em Educação Física) Faculdade de Educação Física. Universidade Estadual de Campinas, Campinas, 2006.

SOARES, Carmen L. Educação Física escolar: conhecimento e especificidade. Revista Paulista de Educação Física, São Paulo, supl. n. 2, p. 6-12, 1996.

SOLER, Reinaldo. Educação física inclusiva: em busca de uma escola plural. Rio de Janeiro: Sprint, 2005. 


\section{PHYSICAL EDUCATION CLASSES AND INCLUSION: SOME DISAGREEMENTS}

ABSTRACT: This paper developed based on a review of the literature about the theoretical production involving Inclusion and school physical education. Questions about the production of this knowledge and meanings about being included guided the debate that confronted different theoretical frameworks. The discussion presented based on authors who conceptualize Inclusion, to pursue school physical education and their encounter with this current concept. Inspired by this theoretical diversity we conclude with the formulation of some considerations about these thoughts in order to contribute with reflections about the theme. Against the failure of diversity we must rethink the concept of Inclusion.

Keywords: Physical Education; Disabled Persons; Cultural diversity

\section{EDUCACIÓN FÍSICA Y INCLUSIÓN: ALGUNOS DESAJUSTES}

RESUMEN: El artículo comprende una revisión de la literatura sobre la producción teórica de Inclusión y clases de educación física. Preguntas acerca de la producción de este conocimiento y significados de ser incluido guiaran el debate que proponemos confrontando marcos teóricos. El debate presentado por autores que conceptualizan Inclusión llega a la educación física escolar y su encuentro ha sido descrito. Inspirados por esta diversidad teórica se concluye con la formulación de consideraciones sobre estos pensamientos a fin de contribuir con reflexiones sobre el tema. Contra el fracaso de la diversidad tenemos que repensar el concepto de Inclusión.

Palabras clave: Educación física; Personas com Discapacidad; Diversidad Cultural. 